\title{
Assessing fundamental motor skills in Belgian children aged 3-8 years highlights differences to US reference sample
}

Farid Bardid ${ }^{1}$, Floris Huyben ${ }^{2}$, Matthieu Lenoir ${ }^{1}$, Jan Seghers ${ }^{3}$, Kristine De Martelaer ${ }^{2}$, Jacqueline D. Goodway ${ }^{4}$, Frederik J.A. Deconinck ${ }^{1,5}$

${ }^{1}$ Department of Movement and Sports Sciences, Ghent University, Belgium

${ }^{2}$ Department of Movement and Sport Sciences, Vrije Universiteit Brussel, Belgium

${ }^{3}$ Department of Kinesiology, KU Leuven - University of Leuven, Belgium

${ }^{4}$ Department of Human Sciences, Kinesiology Division, The Ohio State University, USA

${ }^{5}$ School of Healthcare Science, Manchester Metropolitan University, UK

Corresponding author: Farid Bardid

Ghent University, Faculty of Medicine and Health Sciences, Department of Movement and Sports Sciences, Ghent University, Watersportlaan 2, 9000 Ghent, Belgium

E-mail: farid.bardid@ugent.be 


\begin{abstract}
Aim: This study aimed to understand the fundamental motor skills (FMS) of Belgian children using the process-oriented Test of Gross Motor Development, Second Edition (TGMD-2) and to investigate the suitability of using the United States (US) test norms in Belgium.
\end{abstract}

Methods: FMS were assessed using the TGMD-2. Gender, age and motor performance were examined in 1,614 Belgian children aged three to eight years $(52.1 \%$ boys $)$ and compared with the US reference sample.

Results: More proficient FMS performance was found with increasing age, from three to six years for locomotor skills and three to seven years for object control skills. Gender differences were observed in object control skills, with boys performing better than girls. In general, Belgian children had lower levels of motor competence than the US reference sample, specifically for object control skills. The score distribution of the Belgian sample was skewed, with $37.4 \%$ scoring below average and only $6.9 \%$ scoring above average.

Conclusion: This study supported the usefulness of the TGMD-2 as a process-oriented instrument to measure gross motor development in early childhood in Belgium. However, it also demonstrated that caution is warranted when using the US reference norms. 


\section{Introduction}

Motor competence is defined as the ability to perform a wide range of motor skills (1). Between three and eight years of age, a child's level of motor competence is reflected by their proficiency in fundamental motor skills (FMS), such as locomotor skills and object control skills executed in a bipedal position $(2,3)$. Locomotor skills involve movement through space and include skills such as running and jumping. Object control skills involve manipulation of objects and relate to skills such as catching and kicking. The FMS phase during early childhood is often described in motor development models and is considered important for the long-term development of motor competence and engagement in physical activity across the person's life $(3,4)$. Within this framework, FMS provide the foundation for more complex or specialised motor skills. That is why mastering these skills in the preschool and early elementary school years is crucial to participation and competency in sports, games and other forms of physical activity $(3,4)$.

It is a common misconception that children naturally develop FMS competence through maturation processes (5), whereas in reality they also need practice and instructions to learn and develop FMS. Studies have demonstrated that children progress through developmental sequences while learning these important skills, starting with skills that are inefficient and have little functional utility and progressing to more mechanically efficient skills that can be successfully applied in sports and games (4). Unfortunately, many children do not effectively progress through these sequences and demonstrate delays in FMS development (6).

In their conceptual model, Stodden et al (3) described the dynamic and synergistic relationship between motor competence and physical activity. They considered motor competence to be one of the key underlying mechanisms driving physical activity behaviours throughout childhood and adolescence. This view has been supported by other studies that have 
demonstrated that motor competence was positively associated with levels of physical activity in children. Moreover, longitudinal research has suggested that motor competence in childhood predicts physical activity levels in later life (7). Considering that childhood motor competence contributes to the development of an active lifestyle and concurrent health-related benefits $(3,4)$, it is imperative to assess and monitor motor competence, particularly in early and middle childhood.

Different measurement instruments have been developed to evaluate motor competence (8) and a distinction can be made between product-oriented and process-oriented measurement methods (2). Product-oriented tests focus on the distance, the time or the number of attempts a child takes to successfully execute a motor task, such as the number of successful throws at a target disk. Rather than evaluating the outcome of motor skills, process-oriented tests focus on how motor skills are performed by examining the movement patterns, such as the contralateral step with overhand throw. While both methods contribute to a better understanding of children's motor competence, process-oriented motor assessment looks at motor competence from a developmental perspective. These tests can reveal aspects of a motor skill that have been poorly developed and they can assist in designing instructional interventions. One example of a process-orientated test is the Test of Gross Motor Development, Second Edition (TGMD-2) (9).

The TGMD-2 evaluates the gross motor competence of children with and without disabilities from three to ten years of age (9). The test consists of 12 FMS that are further divided into six locomotor skills, namely run, gallop, hop, leap, horizontal jump and slide, and six object control skills, which are strike, dribble, catch, kick, overhand throw and underhand roll. The test takes about 15 to 20 minutes and only requires equipment that is commonly used in physical activity programmes. The TGMD-2 is both a criterion-referenced and norm-referenced test, as it evaluates a child's performance against a selected set of process criteria for each motor skill and compares the individual scores to the performance of a normative sample (2). The 
normative sample for the TGMD-2 consisted of 1,208 children from the United States (US) and was stratified by age relative to gender, race, region and residence (9). The psychometric properties of the TGMD-2 have been well documented. The test manual reports good test-retest reliability and good inter-rater reliability with $\mathrm{r}$ values of greater than 0.85 . Furthermore, a good to excellent internal consistency has been described in the TGMD-2 manual with Cronbach's alpha coefficients of at least 0.85 . The content, construct and concurrent validity have been established for diverse American and Asian populations and subgroups (9-11).

In Europe, product-oriented measurement instruments, such as the German Körperkoordinationstest für Kinder (KTK) (12), have typically been used to evaluate motor competence in elementary school children (13-15). For example, Vandorpe et al (13) used the KTK to examine motor competence in six to 12-year-old children in Flanders, Belgium. However, empirical evidence on the FMS of younger children in Belgium and other European countries is limited. In light of the scarcity of motor competence data on young children in Europe, the TGMD-2 would be an appropriate instrument for data collection, as it covers the critical age period for FMS development. It also adopts a process-oriented approach to assessing motor competence in early and middle childhood, which has value in the development of future instructional interventions.

When researchers and practitioners adopt a measurement instrument to evaluate motor performance, it is important that they consider the cultural background of the normative sample (16). For example, Vanvuchelen et al (17) administered the Peabody Developmental Motor Scales, Second Edition (PDMS-2) (18) to five-year-old Belgian children and found comparable scores between this cohort and a group from the US, with the exception of visual-motor skills, where the Belgian group performed better. The authors stated that the differences in motor performance could have been explained by the differences in the educational system. In contrast to the US, nearly every child in Belgium attends preschool from the age of three and the 
Organisation for Economic Co-operation and Development (OECD) (19) has reported that publicly-funded preschool education is more developed in European countries than nonEuropean countries such as the US. The majority of these European countries, including Belgium, provide at least two years of free publicly-funded preschool education for all children, which provide them with the opportunities to develop and master motor skills.

The TGMD-2 might be of great use to assess the gross motor competence of typically developing children in European settings, as it uses a process-oriented approach to FMS and provides both criterion-referenced and norm-referenced data, with the noted limitation of the reference sample not being European. Most importantly, these data have translational value in the development of future FMS instructional interventions. Research on the suitability of the TGMD-2 norms for European populations is limited. Simons and Van Hombeeck (20) compared the scores of a Belgian sample of 30, six-year-old children to the US normative sample. Their findings revealed similar locomotor scores, but different scores on the object control subtest with a better performance in the US reference sample. Given the limitations of that study, in particular the small sample size and single age group, further investigations are needed in a European context, with a large sample and broad age range.

In order to better understand motor competence and promote FMS development in a European context, the present study examined the FMS of Belgian children aged three to eight years, from a process-oriented perspective and during a developmentally sensitive age period. The primary aim was to report on the FMS of children from Belgium and investigate possible gender and age-related differences. The secondary aim was to compare the TGMD-2 performance and categorisation of the Belgian sample with the US reference population. Based on the study of Simons and Van Hombeeck (20), we hypothesised that the locomotor scores would be similar, but that the object control score of the Belgian children would be lower than the US normative sample. 


\section{Participants and methods}

\section{Participants}

A large-scale, government-funded initiative project called Multimove for Kids (multimove.be) was set up to examine the motor competence of young children in the Flemish region of Belgium. To obtain a representative sample for this region, 51 settings, including sports clubs, local councils, schools and day care centres, were selected from all five Flemish provinces and the Brussels Capital Region. The study sample consisted of 1,614 children aged three to eight years, with 841 boys and 773 girls. Written, informed consent was obtained from the parents or guardians of each child. The ethics committee of Ghent University Hospital granted permission for this study.

\section{Procedure}

Anthropometric data, namely height and weight, were collected prior to the motor assessment. Height was measured to an accuracy of $0.1 \mathrm{~cm}$ using a SECA 123 portable stadiometer and weight was assessed to an accuracy of $0.1 \mathrm{~kg}$ using a SECA Robusta 813 balance scale (SECA GmbH \& Co KG, Hamburg, Germany). The body mass index (BMI) was calculated from the height and weight values using the following formula: weight / height ${ }^{2}$ $\left(\mathrm{kg} / \mathrm{m}^{2}\right)$ (Table 1). The child's motor competence was assessed with the TGMD-2, in accordance with the detailed instruction manual (9), by trained examiners with a physical education background who had attended a half-day workshop on the TGMD-2. The assessments were coordinated and supervised by the researchers, who were experienced in test assessments. Each test took approximately 20 minutes and was performed in an indoor facility. The assessments were conducted and coded live between September 2012 and November 2012. 


\section{Measurement}

The TGMD-2 covers 12 fundamental motor skills that are divided into two subcategories. The locomotor subtest consists of six skills: running, galloping, hopping, leaping, horizontal jump and slide. The object control subtest also includes six skills: striking a stationary ball, stationary dribble, catching, kicking, overhand throwing and underhand rolling (9). Following a visual demonstration, each child was instructed to perform each of the 12 skills twice. Each skill has three to five critical elements, which were scored by the trained raters on a dichotomous scale: the rater gave a score of one if a critical element was present and a zero if it was not. We calculated the total scores for each skill and for each subtest, ranging from zero to 48. Raw scores for each subtest were then transformed into standard scores, ranging from zero to 20 . Then the locomotor and object control standard scores were added together and converted into a gross motor quotient (GMQ), which had a mean of 100, a standard deviation (SD) of 15 and a range of 46-160. Finally, the GMQ was used to categorise the motor performance of each child, from very poor to very superior (9).

\section{Data analysis}

All analyses were performed using SPSS 20 for Windows (SPSS Inc, Illinois, USA) and the significance level was set at $p \leq 0.05$. Descriptive statics were used to present the TGMD-2 scores. A two-factor ANOVA of the subtest raw scores was performed in order to investigate age and gender differences in the TGMD-2 scores of the Belgian children, based on whether they were three, four, five, six, seven or eight years of age and whether they were a boy or girl. Significant interaction and main effects were further examined with Bonferroni post-hoc tests or pairwise comparisons. One-sample t-tests were used to compare the raw and standard scores for locomotor and object control between the Belgian sample and the US reference population, with the US average as the reference value (9). Finally, chi-square tests were used to evaluate performance categories based on the cut-off points found in the TGMD-2 manual. 


\section{Results}

\section{Influence of age and gender on fundamental motor skills}

Table 2 presents the TGMD-2 item scores and subtest scores for Belgian boys and girls of each age group and the differences are now discussed in accordance with the first aim of the study.

A significant age effect for both locomotor and object control skills indicated different TGMD-2 performance, depending on age: these were locomotor skills $(F=294.998, p<0.001$, partial $\left.\eta^{2}=0.479\right)$ and object control $\left(F=374.131, p<0.001\right.$, partial $\left.\eta^{2}=0.539\right)$. For the locomotor subcategory, post-hoc analysis revealed that four, five, and six-year-old children scored significantly higher than children who were one year younger than them (all $p$ values $<$ $0.001)$ but seven and eight-year-old children did not ( $p=0.106$ and 1.0 respectively). For the object control subcategory, post-hoc tests demonstrated that each age group performed significantly higher than the children who were one year younger than them: all of the $p$ values were $<0.001$, except for the eight versus seven-year-old group where it was $p=0.038$. A significant gender effect for the object control skills indicated that boys scored significantly higher than girls in all age groups $\left(F=275.845, p<0.001\right.$, partial $\left.\eta^{2}=0.147\right)$. A significant interaction between age and gender $\left(F=3.983, p=0.001\right.$, partial $\left.\eta^{2}=0.012\right)$, and the separate follow-up analyses for boys and girls, revealed that only girls in the eight-year-old group scored significantly better on object control skills than the girls who were one year younger than them $(p=0.022)$. Analysis of the children's locomotor skills showed no significant gender differences $(F=2.231, p=0.135)$ and no significant interaction between age and gender $(F=$ $1.083, p=0.368)$. 


\section{Comparison of the Belgian sample and the US reference population}

Figure 1 shows the raw subtest locomotor and object control scores of the Belgian sample in comparison with the US reference population. Differences varied with age when it came to locomotor skills. No significant differences were found between the boys and their US counterparts on the locomotor subtest in the age groups of three $(t=0.961, p=0.338)$, four $(t$ $=1.735, p=0.084)$ and five $(t=1.300, p=0.195)$. Similar findings were recorded for threeyear-old girls $(t=-0.828, p=0.410)$ and four-year-old girls $(t=1.233, p=0.220)$, but fiveyear-old Belgian girls scored significantly higher on locomotor skills than five-year-old girls from the US $(t=4.813, p<0.001$, Cohen's $d=0.4)$. However, the findings showed lower locomotor skill performances for Belgian boys and girls aged six years (boys $t=-5,632, p<$ 0.001 , Cohen's $d=0.446$ and girls $t=-2.193, p=0.030$, Cohen's $d=0.161$ ), seven years (boys $t=-4.036, p<0.001$, Cohen's $d=0.396$ and girls $t=-3.106, p=0.002$, Cohen's $d=0.306)$ and eight years (boys $t=-3.577, p=0.001$, Cohen's $d=0.453$ and girls $t=-9.717, p<0.001$, Cohen's $d=1.095$ ) when compared to their US counterparts. Belgian children of all age groups performed significantly worse on object control skills than the US reference population (all $p$ values $<0.001$, Cohen's $d=0.303-1.269$ ).

In addition to raw scores, analyses were conducted using standard scores based on the US reference population. Table 3 presents the locomotor and object control standard scores and the GMQ for boys and girls in each age group. The mean scores of the locomotor standard score, object control standard score and the GMQ of the US sample were $10 \pm 3,10 \pm 3$ and $100 \pm 15$ respectively. When we compared the subtest standard scores with the US norms (see Table 4), Belgian children scored significantly lower on the locomotor and object control subtests (all $p$ values $<0.001$, Cohen's $d=0.16-0.909)$. Likewise, the GMQ of the Belgian sample was significantly lower than the US sample ( $p<0.001$, Cohen's $d=0.477-0.617$ ). 


\section{TGMD-2 classification of the GMQ scores in the Belgian sample}

Figure 2 shows the distribution of the Belgian children across the TGMD-2 performance categories in comparison to the US reference population. The classification of GMQ according to the TGMD-2 manual (9) consists of seven performance levels. Children with a GMQ of below 70 are rated as having very poor motor competence, 70 and 79 is poor, $80-89$ is below average, $90-110$ is average, $111-120$ is above average, $121-130$ is superior and above 130 indicates very superior motor competence.

Chi-square analyses showed significant differences when we compared the distribution of the Belgian children across the GMQ categories with the distribution according to the TGMD2 manual (chi-square $=219.548, \mathrm{p}<0.001$, Cramer's $\mathrm{V}=0.279$ ). Figure 2 shows that the Belgian sample shifted towards the lower end of the motor continuum. The percentages of the Belgian children in the average, below average and poor categories were higher than the percentages specified by the TGMD-2 US norms (55.9\% versus $49.5 \%, 24.6 \%$ versus $16.1 \%$ and $11.3 \%$ versus $6.9 \%$, respectively). This shift was not present in the very poor category (1.5\% versus $2.3 \%)$. Only $1.3 \%$ of the Belgian children had superior or very superior motor competence in contrast to the $9.2 \%$ in the US reference sample. Furthermore, $16.1 \%$ of the US sample were above average, compared to only $5.3 \%$ of the Belgian sample.

Inspection of the distribution across the categories for the two separate subtests, also showed a shift of the Belgian children's performance towards the lower end for both the locomotor (chi-square $=147.872, p<0.001$, Cramer's $\mathrm{V}=0.229)$ and object control subtests (chi-square $=357.94, p<0.001$, Cramer's $\mathrm{V}=0.356$ ) (Figures 3 and 4). For the locomotor subtest, the percentages of Belgian children in the very superior, superior and above average categories were lower than the percentages in the US sample ( $0.8 \%$ versus $2.3 \%, 2.4 \%$ versus $6.9 \%$ and $8.4 \%$ versus $16.1 \%$, respectively). However, this leftward shift was not present in the remaining categories of below average, poor and very poor and the percentage of Belgian children 
described as having a normal locomotor score was higher compared to the US sample $(68.2 \%$ versus 49.5\%). For the object control subtest, the Belgian distribution was more consistent with the distribution across the GMQ categories. The percentages of Belgian children in the very superior, superior and above average categories were lower than the US reference values, $(0 \%$ versus $2.3 \%, 0.3 \%$ versus $6.9 \%$ and $2 \%$ versus $16.1 \%$, respectively) and higher for the average, below average and poor categories (59.7\% versus $49.5 \%, 27.9 \%$ versus $16.1 \%$ and $8.1 \%$ versus $6.9 \%$, respectively). This shift was not present in the very poor category.

\section{Discussion}

In view of the importance of motor skill development in early and middle childhood, this study evaluated the motor competence of young children in a European context, using the process-oriented TGMD-2. We described the FMS of 1,614 Belgian children aged three to eight years and analysed possible age and gender differences. In addition, we compared the test performance and categorisation of the Belgian sample and the US reference sample.

There were age differences in FMS in the Belgian sample, with children aged three to six years showing an age-related increase in motor performance in both the locomotor and object control subtests. These results were in agreement with previous studies $(15,21)$. In contrast, the similar locomotor performances between children aged six, seven and eight in our cohort disagreed with the findings of Ahnert et al (22) and Vandorpe et al (13), who reported improvements across all ages in elementary school children. It should be noted, however, that both of those studies used the KTK, where the focus of assessment was product-oriented and based on coordination and balance rather than locomotor and object control skills. Indeed, similar skill plateaus for both locomotor and object control scores can be found in the reference population of the TGMD-2 (9). A possible explanation for these findings is that locomotor skills emerge earlier in children's motor development, which may cause a ceiling effect in the 
locomotor subtest of the TGMD-2. As mentioned earlier, most children in Belgium attend preschool at the age of three and preschool activities may enable children to develop locomotor skills earlier. However, these skills might stabilise over time as children enter elementary school and their focus on motor instruction shifts to object control related activities. This assumption is partly supported by the results of the object control scores in the present study, where a gradual improvement across all age groups was found, except for eight-year-old boys who showed no difference to the seven-year-old boys.

In agreement with prior research $(6,23)$, findings on gender differences indicated similar locomotor scores for Belgian boys and girls, while object control scores were higher for boys. Although gender differences in motor performance have been classified as an individual constraint due to the biological factors related to them (4), physical characteristics such as body type, body composition, strength and limb lengths are quite similar between prepubertal boys and girls (24). Therefore, researchers have argued that gender differences before puberty are more likely to be associated with socio-cultural factors such as a child's perception of their appropriate gender role with regard to sports and games (25). Children learn a gender role from their family, peers and teachers or coaches through socialisation and imitation and consequently participate in activities that fit these gender norms (26). Therefore, a possible explanation for the gender differences in object control skills was that boys engage in more object control related activities, such as ball games, than girls and therefore have more opportunities to practice and develop these skills. The gender-related results observed in the Belgian sample were in line with the findings in the normative sample of the TGMD-2, which supports the use of separate object control norms for boys and girls (9).

To examine the suitability of the TGMD-2 in a European context, we compared the raw and standardised scores of the Belgian sample with the US reference population. The findings were not straightforward as the results varied by age and subtests. In the three to five year age group, 
the scores for the Belgian children's locomotor skills were similar to those of the US children, but the US children were significantly better when it came to object control skills. These findings were consistent with the study by Simons and Van Hombeeck (20) who suggested that differences in object control skills might be attributed to Belgian children's lack of experience with some object control skills in the TGMD-2, mainly striking with a bat and overarm throwing, that are prominent in sports like baseball and softball, popular in the US but not in Belgium. In the older age group of six to eight years in the present study, the results showed that Belgian children scored lower on locomotor and object control skills than the US reference group.

The lower TGMD-2 scores of the Belgian sample compared to the US reference sample indicated that cultural factors may play an important role in differences between children from distinct regions. For instance, when we compared our Belgian sample with the Brazilian sample from the 2012 study by Valentini et al (10), the raw locomotor scores for the Belgian sample was $11-32 \%$ higher, depending on age, than the Brazilian sample and Belgian children scored 2-31\% higher for object control. Although Belgian and Brazilian sports cultures are more similar to each other, with soccer being the most popular sport, than between those two countries and the US, the observed differences in motor scores can be related to differences in the early childhood education systems. Structured and unstructured activities in a school environment enable children to learn and develop motor skills. According to the 2013 OECD report (19), 98-99\% of Belgian children aged three to five years were enrolled in early childhood education, while the enrolment rates in Brazil were $37 \%, 57 \%$ and $80 \%$ for the ages of three, four and five, respectively. Nonetheless, Belgian children did score lower on the TGMD-2 than children from the US, even though the enrolment rates of three, four and fiveyear-olds in early childhood education were lower in the US, at $50 \%, 78 \%$ and $83 \%$, 
respectively (19). However, young children can also practice and develop motor skills through structured and unstructured physical activity outside the school setting.

The lower TGMD performance in the Belgian sample might also have been due to a decline in motor competence, as observed in Western countries $(13,27,28)$. Because there was a time gap of approximately 15 years between the data collection of the US reference sample (19971998) and the Belgian sample (2012), it could be argued that the lower TGMD-2 performance of the Belgian children might have been due to a secular decrease in motor competence. In turn, this trend might have been related to the decrease of physical activity in contexts such as active transport, physical education and organised sports in many countries (29). Physical activity provides opportunities to practice FMS and gain motor competency, but the observed secular trend might hamper children mastering these skills. In addition, Stodden et al (3) stated that the relationship between motor competence and physical activity strengthens over time, which might explain the discrepancy between the younger and older age groups - three to five years versus six to eight years - when comparing their locomotor scores. Future research is needed to examine the relative impact of cultural trends, such as sports culture, organised sports and education systems, and secular trends in FMS competence.

Our investigation of the suitability of the TGMD-2 cut-off points demonstrated differences in the distribution of the performance categories of the Belgian and US samples. The results showed a shift in the Belgian distribution towards the lower end of the motor competence spectrum, indicating that a larger portion of Belgian children scored below average compared to the US children. In addition, a lower percentage of the Belgian sample scored above average. This shift was also observed in the object control subtest and, to a smaller degree, in the locomotor subtest. Interestingly, no Belgian child was categorised as having a very superior GMQ or object control skills. It is also remarkable that the distribution shift towards the lower end of the continuum was not apparent in the very poor category. Our findings indicate that 
these TGMD-2 categories at the lowest and highest end of the motor competence spectrum, namely very poor and very superior, may not have been sufficiently discriminative in a Belgian sample. Nevertheless, the shift towards lower levels of motor performance might have been related to a cultural bias of the TGMD-2 towards the US sports context and our findings do not necessarily imply that we should just adjust the norms for Belgian children. The criterion elements of the TGMD-2 outline proficient performance of FMS. Thus, if we were to lower the norms for the Belgian sample we would not be advocating for the most proficient patterns of performance for these skills. Vandorpe et al (13) stated that instead of lowering the norms, we should focus on developing motor skills in order to help as many children as possible to achieve a sufficient level of gross motor competence. Such a view is supported by the literature (3), which suggests that the development of motor competence in the early years is critical to engagement in physical activity and perceived motor competence. In this respect, the TGMD2 can provide a useful measurement instrument to assess FMS in a developmental manner and provide the possibility of evaluating if a child's gross motor competence fits within a normal range by means of its reference values.

The findings of our study provide valuable information on the use of a process-oriented evaluation of gross motor competence in Belgium and potential cultural differences between the Belgian sample and the US reference sample. Given that cultural influences on motor development, such as the range of sporting activities, are similar in Belgium and the rest of Europe, our findings of weaker object control skills may potentially be extrapolated to other European regions. Although the use of a standardised worldwide assessment could allow for direct comparisons between countries, it is also important to understand to what degree a test battery is biased towards a specific cultural context. For instance, the cross-cultural study carried out by Bardid et al (27) using the German KTK test, demonstrated that Belgian children performed better than Australian children when it came to motor coordination, which may 
support the notion that the Belgian elementary physical education curriculum enhanced Belgian children's motor coordination but not their object control skills. Moreover, Rudd et al (30) put forward a holistic model of motor competence that supported the need to measure both motor coordination and FMS in order to develop a more comprehensive understanding of motor competence. Future research efforts are required to study the impact of cultural differences on measuring motor competence in a broader international context. A limitation of our study was that the children's TGMD-2 performance was not video-recorded for later assessment and this means that it was not possible to report inter-rater reliability in this study.

\section{Conclusion}

This study provides information on early childhood motor development in a European context using a process-oriented perspective. Representative values on the TGMD-2 test were provided for Belgian children, with a performance improvement from three to six years in the locomotor subtest and three to seven years in the object control subtest. Gender differences in the object control subtest confirm the need for separate TGMD-2 norms for boys and girls with these skills. In general, Belgian children scored lower on motor competence than the US reference sample, especially for the object control subtest, which may be explained by cultural differences in physical activity contexts or a downward trend in motor competence. These findings were further highlighted by a shift in the Belgian children's performance toward the lower end of the motor competence continuum. The present study supported the usefulness of the TGMD-2 as a process-oriented instrument to measure gross motor development in early childhood in Belgium. However, it also demonstrated that caution is warranted when using the US reference norms. Although we could consider the development of separate norms for Belgian children, it is more valuable to focus on providing instructional programmes that develop FMS and motor competency in early and middle childhood, in order to prepare children for future sports and games (3). 


\section{Acknowledgments}

We wish to thank students Brecht Ameys, Wout Chielens, Sara Dauwe, Hanne De Ruyck, Eline Sarrazyn and Anouk Vanblaere for assisting with the data collection, the children and parents who took part and the staff of the participating organisations.

\section{Finance}

This research was funded by the Flemish Government.

\section{Conflicts of interest}

The authors have no conflicts of interests to declare. 
Table 1

Descriptive statistics - means (M) and standard deviations (SD) - of anthropometric measurements for boys and girls, stratified by age.

\begin{tabular}{|c|c|c|c|c|c|}
\hline \multirow[b]{2}{*}{ Age } & \multirow[b]{2}{*}{ Variables } & \multicolumn{2}{|c|}{ Boys } & \multicolumn{2}{|c|}{ Girls } \\
\hline & & $\mathrm{M}$ & SD & M & SD \\
\hline \multirow{3}{*}{3 years } & Height (cm) & 100.8 & 4.5 & 99.0 & 4.5 \\
\hline & Weight (kg) & 16.6 & 2.0 & 15.9 & 2.1 \\
\hline & BMI $\left(\mathrm{kg} / \mathrm{m}^{2}\right)$ & 16.27 & 1.17 & 16.21 & 1.34 \\
\hline \multirow[t]{3}{*}{4 years } & Height (cm) & 106.9 & 4.6 & 106.4 & 4.5 \\
\hline & Weight (kg) & 18.5 & 2.4 & 18.3 & 2.5 \\
\hline & BMI $\left(\mathrm{kg} / \mathrm{m}^{2}\right)$ & 16.08 & 1.27 & 16.09 & 1.48 \\
\hline \multirow[t]{3}{*}{5 years } & Height (cm) & 113.7 & 4.9 & 113.0 & 5.1 \\
\hline & Weight (kg) & 20.6 & 2.8 & 20.1 & 3.0 \\
\hline & BMI $\left(\mathrm{kg} / \mathrm{m}^{2}\right)$ & 15.89 & 1.42 & 15.69 & 1.55 \\
\hline \multirow[t]{3}{*}{6 years } & Height (cm) & 120.5 & 5.4 & 119.9 & 5.8 \\
\hline & Weight (kg) & 23.1 & 3.5 & 23.4 & 4.2 \\
\hline & BMI $\left(\mathrm{kg} / \mathrm{m}^{2}\right)$ & 15.83 & 1.69 & 16.17 & 1.90 \\
\hline \multirow[t]{3}{*}{7 years } & Height (cm) & 126.8 & 6.3 & 125.7 & 5.7 \\
\hline & Weight (kg) & 26.5 & 5.3 & 26.6 & 5.1 \\
\hline & BMI $\left(\mathrm{kg} / \mathrm{m}^{2}\right)$ & 16.38 & 2.05 & 16.79 & 2.50 \\
\hline \multirow[t]{3}{*}{8 years } & Height (cm) & 132.6 & 6.0 & 131.4 & 6.3 \\
\hline & Weight (kg) & 28.7 & 5.2 & 29.7 & 6.4 \\
\hline & BMI $\left(\mathrm{kg} / \mathrm{m}^{2}\right)$ & 16.23 & 2.10 & 17.09 & 2.60 \\
\hline
\end{tabular}


Table 2

Means (M) and standard deviations (SD) of performance on the TGMD-2 - item scores and subtest scores - for all age groups.

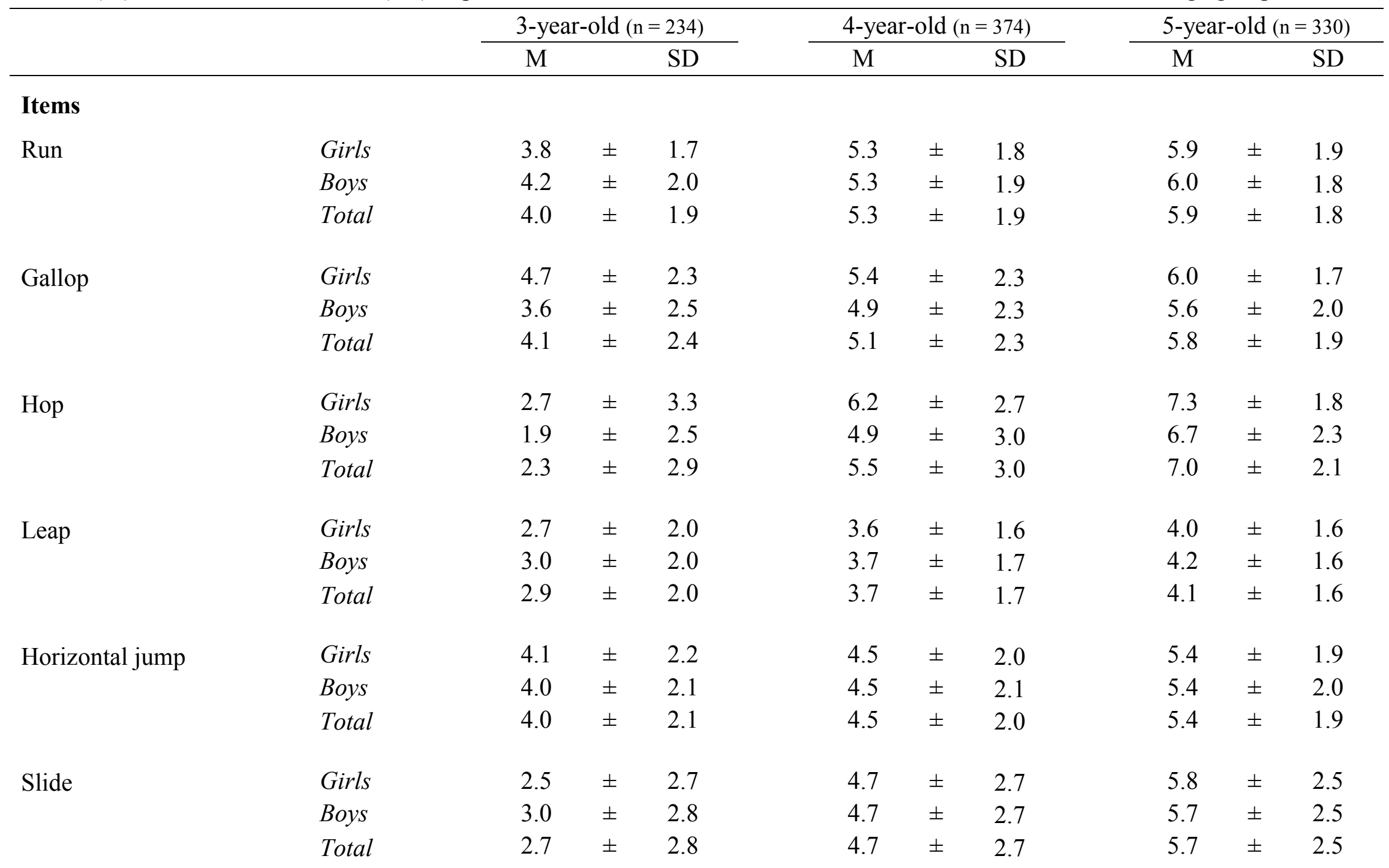




\begin{tabular}{|c|c|c|c|c|c|c|c|c|c|c|}
\hline \multirow[t]{3}{*}{ Striking a stationary ball } & Girls & 3.7 & \pm & 2.5 & 5.1 & \pm & 2.2 & 6.1 & \pm & 2.3 \\
\hline & Boys & 4.8 & \pm & 2.6 & 5.5 & \pm & 2.2 & 6.7 & \pm & 2.3 \\
\hline & Total & 4.3 & \pm & 2.6 & 5.3 & \pm & 2.2 & 6.4 & \pm & 2.3 \\
\hline \multirow[t]{3}{*}{ Stationary dribble } & Girls & 0.5 & \pm & 1.1 & 1.2 & \pm & 1.7 & 1.8 & \pm & 2.0 \\
\hline & Boys & 0.7 & \pm & 1.5 & 1.6 & \pm & 2.0 & 2.9 & \pm & 2.6 \\
\hline & Total & 0.6 & \pm & 1.3 & 1.4 & \pm & 1.9 & 2.4 & \pm & 2.4 \\
\hline \multirow[t]{3}{*}{ Catch } & Girls & 1.8 & \pm & 1.4 & 2.1 & \pm & 1.5 & 3.2 & \pm & 1.5 \\
\hline & Boys & 2.0 & \pm & 1.5 & 2.7 & \pm & 1.5 & 3.4 & \pm & 1.6 \\
\hline & Total & 1.9 & \pm & 1.4 & 2.4 & \pm & 1.5 & 3.3 & \pm & 1.6 \\
\hline \multirow[t]{3}{*}{ Kick } & Girls & 3.2 & \pm & 1.7 & 3.5 & \pm & 1.6 & 4.2 & \pm & 1.6 \\
\hline & Boys & 3.9 & \pm & 1.8 & 4.8 & \pm & 1.9 & 5.5 & \pm & 1.7 \\
\hline & Total & 3.6 & \pm & 1.8 & 4.2 & \pm & 1.9 & 4.9 & \pm & 1.8 \\
\hline \multirow[t]{3}{*}{ Overhand throw } & Girls & 1.8 & \pm & 1.5 & 2.5 & \pm & 1.9 & 3.4 & \pm & 2.1 \\
\hline & Boys & 2.5 & \pm & 1.8 & 3.5 & \pm & 2.2 & 4.4 & \pm & 2.2 \\
\hline & Total & 2.2 & \pm & 1.7 & 3.1 & \pm & 2.1 & 3.9 & \pm & 2.2 \\
\hline \multirow[t]{3}{*}{ Underhand roll } & Girls & 3.1 & \pm & 1.6 & 3.8 & \pm & 1.7 & 4.6 & \pm & 1.7 \\
\hline & Boys & 3.6 & \pm & 1.9 & 4.3 & \pm & 1.8 & 4.6 & \pm & 1.8 \\
\hline & Total & 3.3 & \pm & 1.8 & 4.1 & \pm & 1.8 & 4.6 & \pm & 1.7 \\
\hline \multicolumn{11}{|l|}{ Subtests } \\
\hline \multirow[t]{3}{*}{ Locomotor } & Girls & 20.4 & \pm & 8.0 & 29.7 & \pm & 6.9 & 34.4 & \pm & 6.0 \\
\hline & Boys & 19.7 & \pm & 7.7 & 28.0 & \pm & 8.1 & 33.6 & \pm & 6.3 \\
\hline & Total & 20.0 & \pm & 7.8 & 28.7 & \pm & 7.6 & 34.0 & \pm & 6.2 \\
\hline
\end{tabular}




\begin{tabular}{|c|c|c|c|c|c|c|c|c|c|c|}
\hline \multirow[t]{3}{*}{ Object control } & Girls & 14.1 & \pm & 5.3 & 18.1 & \pm & 5.3 & 23.3 & \pm & 5.6 \\
\hline & Boys & 17.5 & \pm & 6.3 & 22.3 & \pm & 6.0 & 27.4 & \pm & 6.4 \\
\hline & Total & 15.9 & \pm & 6.0 & 20.5 & \pm & 6.1 & 25.6 & \pm & 6.4 \\
\hline
\end{tabular}


Table 2 (continued)

\begin{tabular}{|c|c|c|c|c|c|c|c|c|c|c|}
\hline & & \multicolumn{3}{|c|}{ 6-year-old $(n=323)$} & \multicolumn{3}{|c|}{ 7-year-old $(n=210)$} & \multicolumn{3}{|c|}{ 8-year-old $(n=143)$} \\
\hline & & \multicolumn{2}{|l|}{ M } & \multirow[t]{2}{*}{ SD } & \multirow[t]{2}{*}{ M } & & \multirow[t]{2}{*}{ SD } & \multirow[t]{2}{*}{$\mathrm{M}$} & & \multirow[t]{2}{*}{ SD } \\
\hline Items & & & & & & & & & & \\
\hline \multirow[t]{3}{*}{ Run } & Girls & 6.2 & \pm & 1.9 & 6.5 & \pm & 1.5 & 6.1 & \pm & 1.6 \\
\hline & Boys & 6.4 & \pm & 1.8 & 6.5 & \pm & 1.6 & 6.8 & \pm & 1.4 \\
\hline & Total & 6.3 & \pm & 1.9 & 6.5 & \pm & 1.5 & 6.4 & \pm & 1.6 \\
\hline \multirow[t]{3}{*}{ Gallop } & Girls & 6.2 & \pm & 1.8 & 6.2 & \pm & 1.7 & 6.3 & \pm & 1.5 \\
\hline & Boys & 5.8 & \pm & 2.0 & 6.4 & \pm & 1.5 & 6.4 & \pm & 1.7 \\
\hline & Total & 6.0 & \pm & 1.9 & 6.3 & \pm & 1.6 & 6.3 & \pm & 1.5 \\
\hline \multirow[t]{3}{*}{ Нор } & Girls & 8.2 & \pm & 1.6 & 8.4 & \pm & 1.5 & 8.2 & \pm & 1.5 \\
\hline & Boys & 8.0 & \pm & 1.6 & 8.2 & \pm & 1.6 & 8.5 & \pm & 1.5 \\
\hline & Total & 8.1 & \pm & 1.6 & 8.3 & \pm & 1.5 & 8.3 & \pm & 1.5 \\
\hline \multirow[t]{3}{*}{ Leap } & Girls & 4.3 & \pm & 1.4 & 4.6 & \pm & 1.5 & 4.8 & \pm & 1.2 \\
\hline & Boys & 4.3 & \pm & 1.4 & 4.3 & \pm & 1.4 & 4.5 & \pm & 1.6 \\
\hline & Total & 4.3 & \pm & 1.4 & 4.4 & \pm & 1.4 & 4.7 & \pm & 1.4 \\
\hline \multirow[t]{3}{*}{ Horizontal jump } & Girls & 5.6 & \pm & 1.8 & 5.8 & \pm & 1.7 & 6.1 & \pm & 1.9 \\
\hline & Boys & 5.4 & \pm & 1.9 & 5.8 & \pm & 1.9 & 6.2 & \pm & 1.8 \\
\hline & Total & 5.5 & \pm & 1.8 & 5.8 & \pm & 1.8 & 6.2 & \pm & 1.8 \\
\hline \multirow[t]{3}{*}{ Slide } & Girls & 6.6 & \pm & 2.1 & 7.0 & \pm & 1.8 & 7.0 & \pm & 1.7 \\
\hline & Boys & 6.5 & \pm & 2.0 & 7.1 & \pm & 1.5 & 7.2 & \pm & 1.7 \\
\hline & Total & 6.6 & \pm & 2.0 & 7.0 & \pm & 1.6 & 7.1 & \pm & 1.7 \\
\hline
\end{tabular}




\begin{tabular}{|c|c|c|c|c|c|c|c|c|c|c|}
\hline \multirow[t]{3}{*}{ Striking a stationary ball } & Girls & 6.4 & \pm & 2.2 & 6.4 & \pm & 2.1 & 6.8 & \pm & 2.2 \\
\hline & Boys & 6.9 & \pm & 2.3 & 8.1 & \pm & 2.0 & 7.6 & \pm & 2.2 \\
\hline & Total & 6.6 & \pm & 2.3 & 7.2 & \pm & 2.2 & 7.1 & \pm & 2.3 \\
\hline \multirow[t]{3}{*}{ Stationary dribble } & Girls & 3.2 & \pm & 2.6 & 4.6 & \pm & 2.4 & 5.6 & \pm & 2.2 \\
\hline & Boys & 5.1 & \pm & 2.6 & 6.0 & \pm & 2.2 & 6.6 & \pm & 1.7 \\
\hline & Total & 4.1 & \pm & 2.7 & 5.3 & \pm & 2.4 & 6.0 & \pm & 2.0 \\
\hline \multirow[t]{3}{*}{ Catch } & Girls & 3.7 & \pm & 1.7 & 4.3 & \pm & 1.6 & 4.8 & \pm & 1.3 \\
\hline & Boys & 4.3 & \pm & 1.5 & 4.6 & \pm & 1.4 & 5.0 & \pm & 1.2 \\
\hline & Total & 4.0 & \pm & 1.6 & 4.4 & \pm & 1.5 & 4.9 & \pm & 1.3 \\
\hline \multirow[t]{3}{*}{ Kick } & Girls & 4.8 & \pm & 1.8 & 4.6 & \pm & 1.7 & 4.7 & \pm & 1.6 \\
\hline & Boys & 6.2 & \pm & 1.6 & 6.2 & \pm & 1.8 & 6.6 & \pm & 1.4 \\
\hline & Total & 5.5 & \pm & 1.9 & 5.4 & \pm & 1.9 & 5.5 & \pm & 1.8 \\
\hline \multirow[t]{3}{*}{ Overhand throw } & Girls & 3.6 & \pm & 1.9 & 4.7 & \pm & 2.1 & 4.8 & \pm & 2.1 \\
\hline & Boys & 5.3 & \pm & 1.9 & 5.8 & \pm & 1.9 & 6.3 & \pm & 1.7 \\
\hline & Total & 4.4 & \pm & 2.1 & 5.3 & \pm & 2.1 & 5.5 & \pm & 2.1 \\
\hline \multirow[t]{3}{*}{ Underhand roll } & Girls & 4.9 & \pm & 1.7 & 5.0 & \pm & 1.6 & 5.7 & \pm & 1.6 \\
\hline & Boys & 5.4 & \pm & 1.5 & 5.7 & \pm & 1.6 & 6.0 & \pm & 1.6 \\
\hline & Total & 5.1 & \pm & 1.6 & 5.4 & \pm & 1.6 & 5.8 & \pm & 1.6 \\
\hline \multicolumn{11}{|l|}{ Subtests } \\
\hline \multirow[t]{3}{*}{ Locomotor } & Girls & 37.1 & \pm & 5.6 & 38.5 & \pm & 4.9 & 38.4 & \pm & 4.2 \\
\hline & Boys & 36.5 & \pm & 5.6 & 38.1 & \pm & 4.8 & 39.6 & \pm & 5.3 \\
\hline & Total & 36.8 & \pm & 5.6 & 38.3 & \pm & 4.9 & 38.9 & \pm & 4.7 \\
\hline
\end{tabular}


Object control

$\begin{array}{llll}\text { Girls } & 26.5 & \pm & 5.8 \\ \text { Boys } & 33.1 & \pm & 6.4 \\ \text { Total } & 29.8 & \pm & 7.0\end{array}$

$29.7 \pm 6.1$

$36.4 \pm 5.6$

$33.0 \pm 6.7$

$32.4 \pm 5.2$

$38.1 \pm 4.6$

$29.8 \pm 7.0$

$34.9 \pm \quad 5.7$ 
Table 3

Means (M) and standard deviations (SD) of TGMD-2 standardised scores - subtests and Gross Motor Quotient (GMQ) - for all age groups.

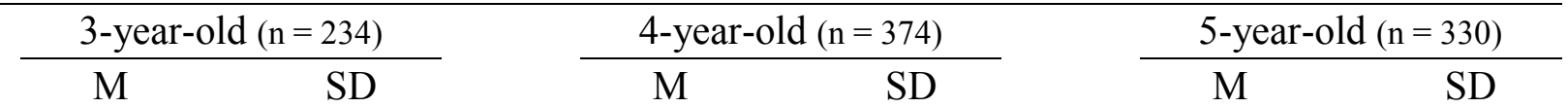

\section{Subtests}

Locomotor

$\begin{array}{llll}\text { Girls } & 9.6 & \pm & 2.4 \\ \text { Boys } & 9.2 & \pm & 2.3 \\ \text { Total } & 9.4 & \pm & 2.4\end{array}$

$10.6 \pm 2.4$

$10.0 \pm 2.7$

$10.2 \pm 2.6$

$10.3 \pm 2.4$

Total

$8.9 \pm 1.8$

Object Control

$\begin{array}{llll}\text { Girls } & 8.9 & \pm & 1.8 \\ \text { Boys } & 8.9 & \pm & 2.0 \\ \text { Total } & 8.9 & \pm & 1.9\end{array}$

$8.2 \pm 1.8$

$8.7 \pm 2.0$

$8.5 \pm 1.9$

$10.0 \pm 2.3$

Total

$95.4 \pm 10.4$

$\begin{array}{llll}\text { Girls } & 95.4 & \pm & 10.4 \\ \text { Boys } & 94.4 & \pm & 10.5 \\ \text { Total } & 94.9 & \pm & 10.5\end{array}$

$96.3 \pm 10.3$

$96.1 \pm 11.6$

$10.2 \pm \quad 2.4$

Total

$96.2 \pm 11.1$

$\begin{array}{lll}8.2 & \pm & 2.2 \\ 8.4 & \pm & 2.0 \\ 8.3 & \pm & 2.1\end{array}$

$95.5 \pm 10.8$

$95.4 \pm 10.6$

$95.5 \pm 10.7$ 
Table 3 (continued)

\begin{tabular}{|c|c|c|c|c|c|c|c|c|c|c|}
\hline & & \multicolumn{3}{|c|}{ 6-year-old $(n=323)$} & \multicolumn{3}{|c|}{ 7-year-old $(n=210)$} & \multicolumn{3}{|c|}{ 8-year-old $(n=143)$} \\
\hline & & $\mathrm{M}$ & & SD & $\mathrm{M}$ & & $\mathrm{SD}$ & $\mathrm{M}$ & & $\mathrm{SD}$ \\
\hline \multicolumn{11}{|l|}{ Subtests } \\
\hline \multirow[t]{3}{*}{ Locomotor } & Girls & 9.5 & \pm & 2.5 & 9.0 & \pm & 2.3 & 7.8 & \pm & 2.2 \\
\hline & Boys & 9.4 & \pm & 2.4 & 8.7 & \pm & 2.3 & 8.5 & \pm & 2.7 \\
\hline & Total & 9.5 & \pm & 2.4 & 8.8 & \pm & 2.3 & 8.1 & \pm & 2.5 \\
\hline \multirow{3}{*}{ Object Control } & Girls & 7.8 & \pm & 2.3 & 7.4 & \pm & 2.5 & 7.0 & \pm & 2.4 \\
\hline & Boys & 8.3 & \pm & 2.2 & 7.7 & \pm & 2.3 & 7.1 & \pm & 2.1 \\
\hline & Total & 8.0 & \pm & 2.3 & 7.5 & \pm & 2.4 & 7.1 & \pm & 2.3 \\
\hline \multirow[t]{3}{*}{ GMQ } & Girls & 91.9 & \pm & 11.8 & 89.1 & \pm & 11.6 & 84.3 & \pm & 9.8 \\
\hline & Boys & 93.0 & \pm & 10.9 & 89.0 & \pm & 10.2 & 86.8 & \pm & 11.7 \\
\hline & Total & 92.5 & \pm & 11.4 & 89.1 & \pm & 10.9 & 85.4 & \pm & 10.7 \\
\hline
\end{tabular}


Table 4

Results of the one-sample t-test analysis comparing the TGMD-2 standard scores of Belgian children and the US norms $(10 \pm 3,10 \pm 3$ and $100 \pm 15$ for locomotor, object control and GMQ respectively).

\begin{tabular}{lllllll}
\hline & & M & & SD & $t$ & $p$ \\
\hline Subtests & & & & & & \\
Locomotor & Girls $(\mathrm{n}=773)$ & 9.6 & \pm & 2.5 & -4.073 & $<0.001$ \\
& Boys $(\mathrm{n}=841)$ & 9.5 & \pm & 2.5 & -5.727 & $<0.001$ \\
& Total $(\mathrm{n}=1,614)$ & 9.6 & \pm & 2.5 & -6.948 & $<0.001$ \\
& & & & & & \\
Object control & Girls $(\mathrm{n}=773)$ & 8.0 & \pm & 2.2 & -24.939 & $<0.001$ \\
& Boys $(\mathrm{n}=841)$ & 8.4 & \pm & 2.1 & -22.514 & $<0.001$ \\
& Total $(\mathrm{n}=1,614)$ & 8.2 & \pm & 2.2 & -33.458 & $<0.001$ \\
& & & & & & \\
GMQ & Girls $(\mathrm{n}=773)$ & 92.9 & \pm 11.5 & -17.275 & $<0.001$ \\
& Boys $(\mathrm{n}=841)$ & 93.6 & \pm 11.3 & -13.902 & $<0.001$ \\
& Total $(\mathrm{n}=1,614)$ & 93.2 & \pm 11.4 & -23.845 & $<0.001$ \\
\hline
\end{tabular}


Locomotor skills Boys

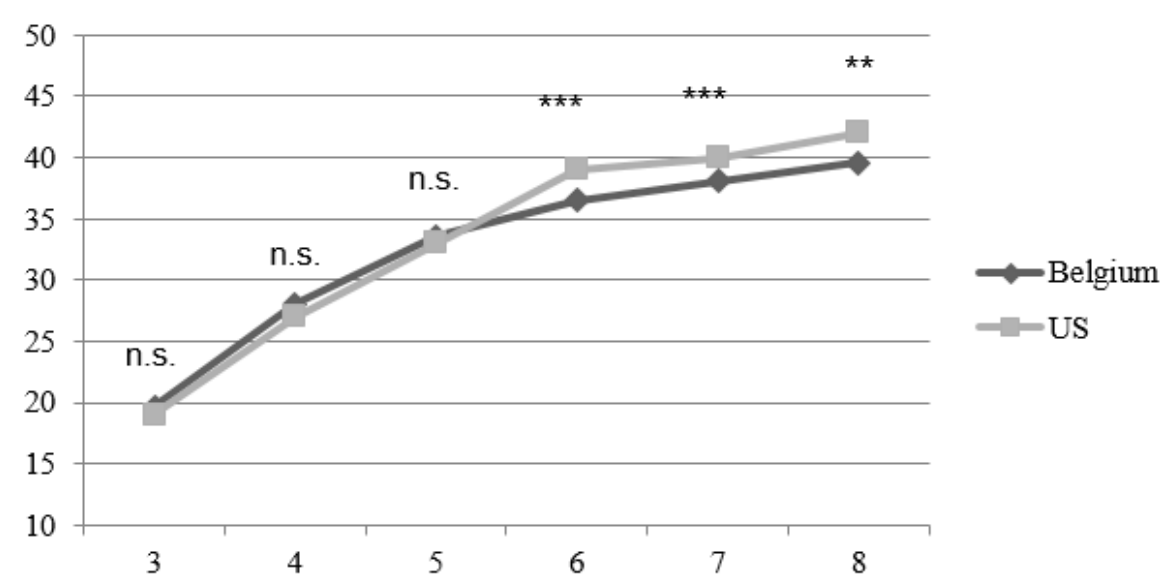

Object control skills Boys

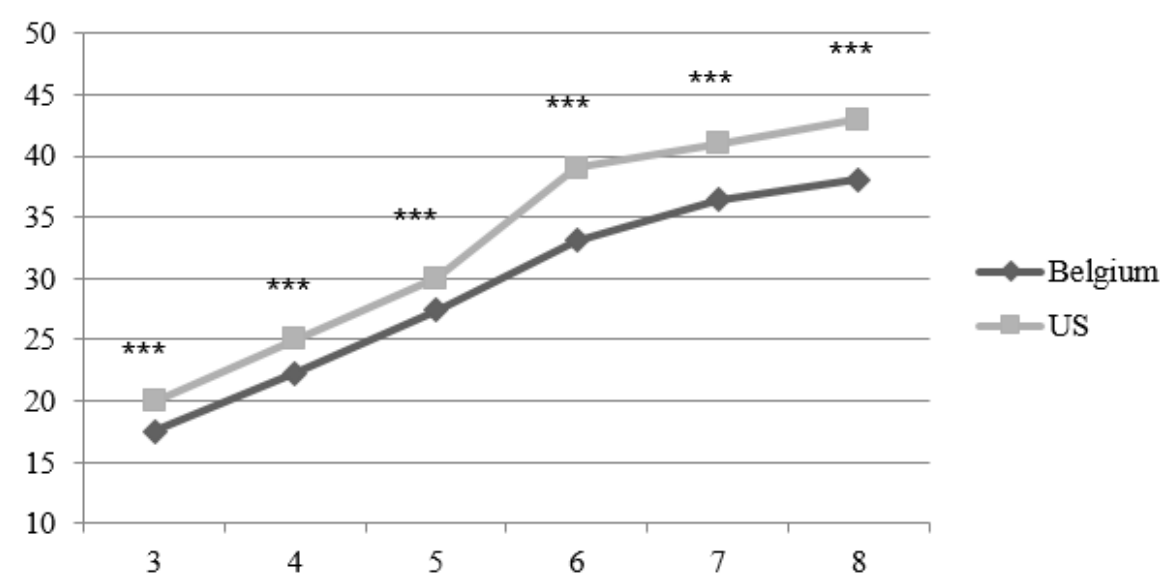

Locomotor skills Girls

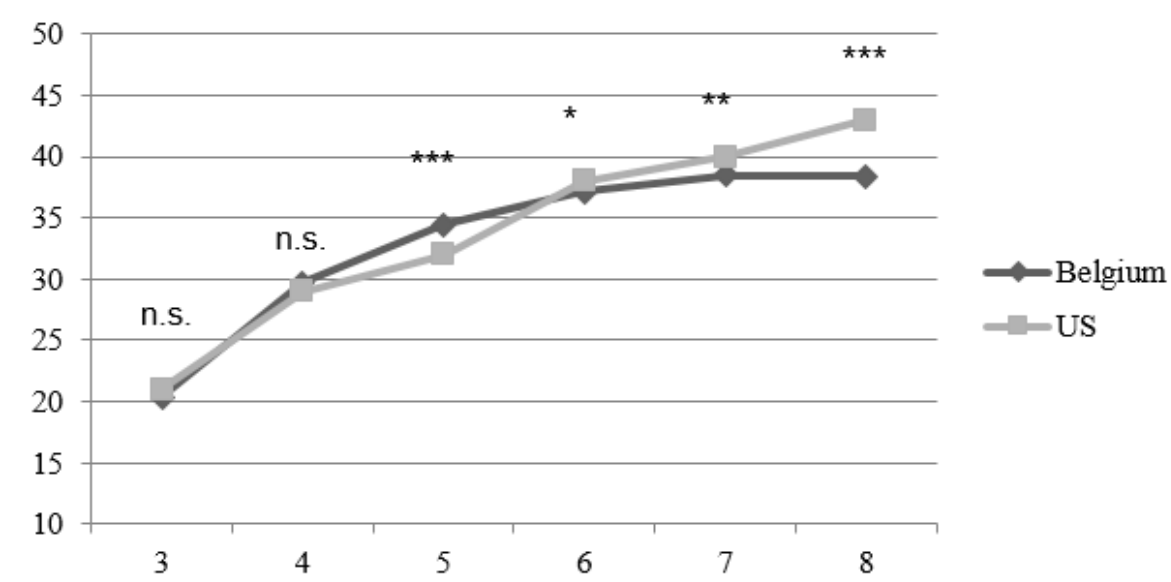

Object control skills Girls

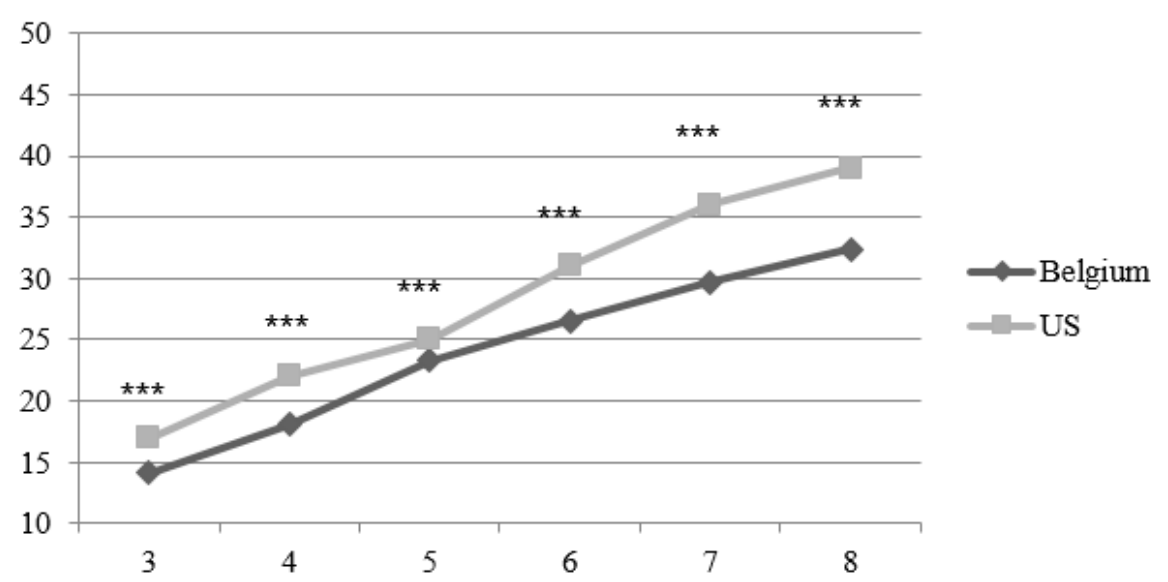

Fig 1. Comparison of locomotor and object control raw scores between the Belgian sample and the US reference population. ${ }^{* * *} p<0.001 ; * * p<0.01 ;{ }^{*} p \leq 0.05 ;$ n.s., not significant $(p>0.05)$. 


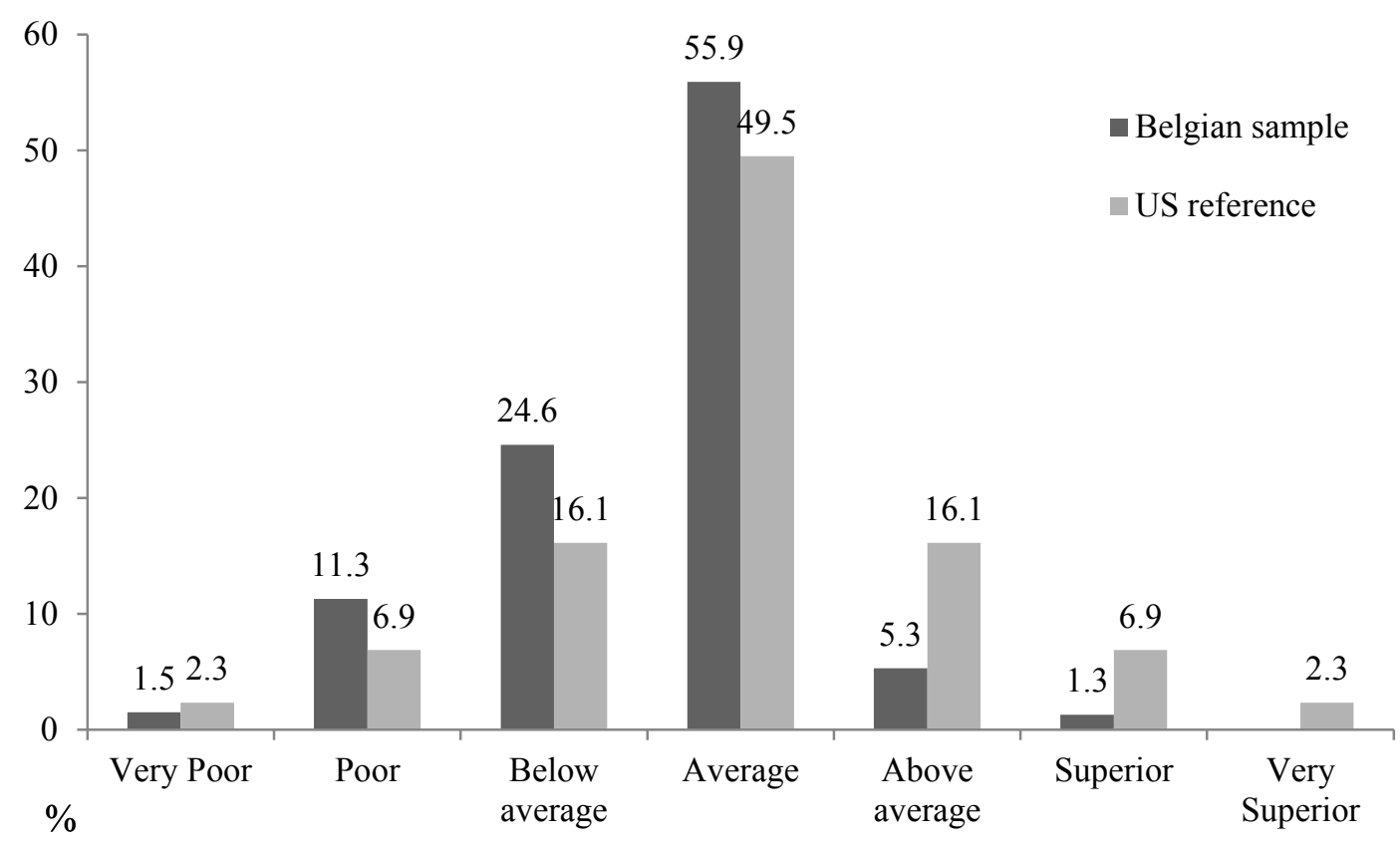

Fig 2. Distribution of Belgian children across the TGMD-2 performance categories for Gross Motor Quotient (GMQ).

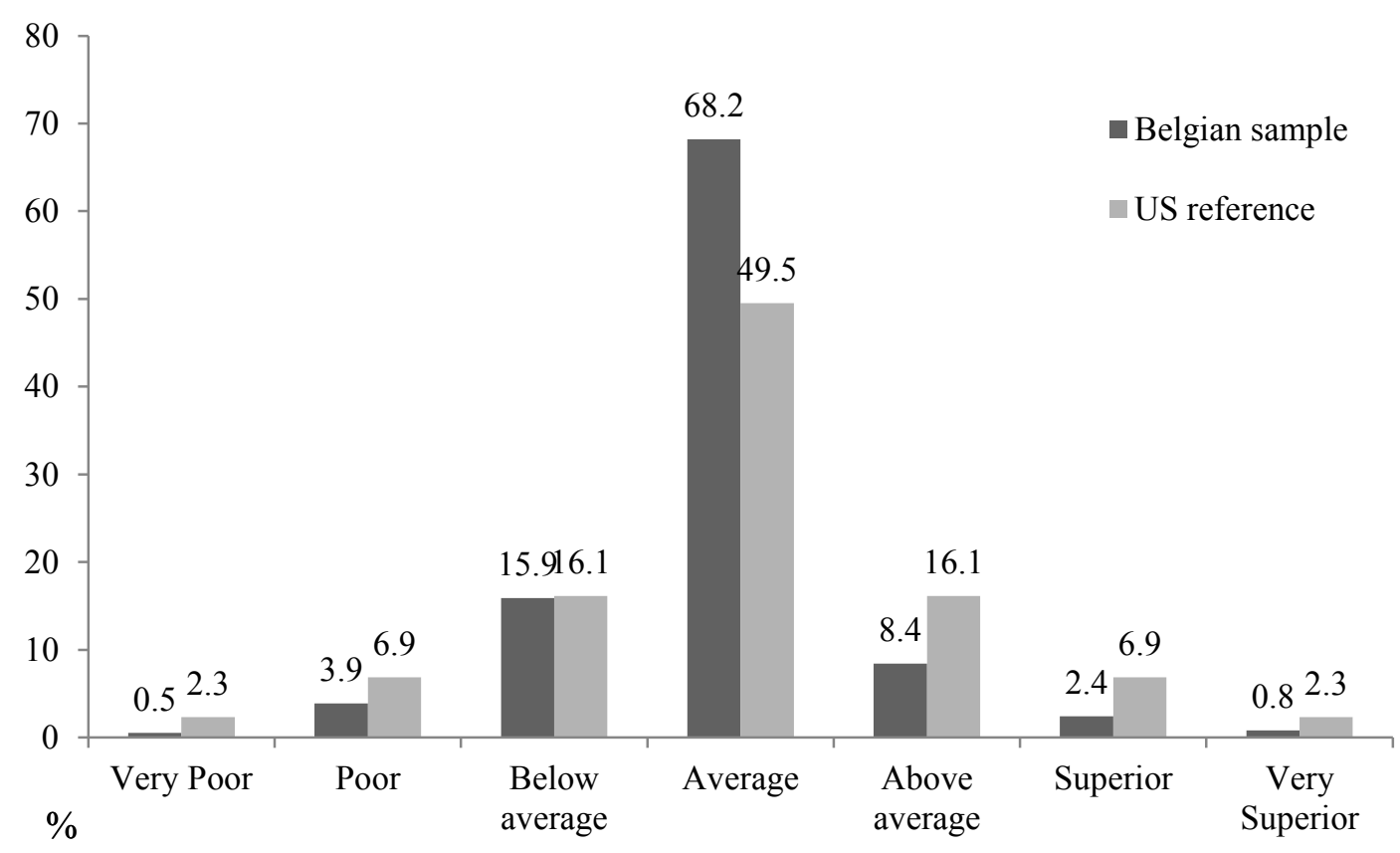

Fig 3. Distribution of Belgian children across the TGMD-2 performance categories for the locomotor subtest. 


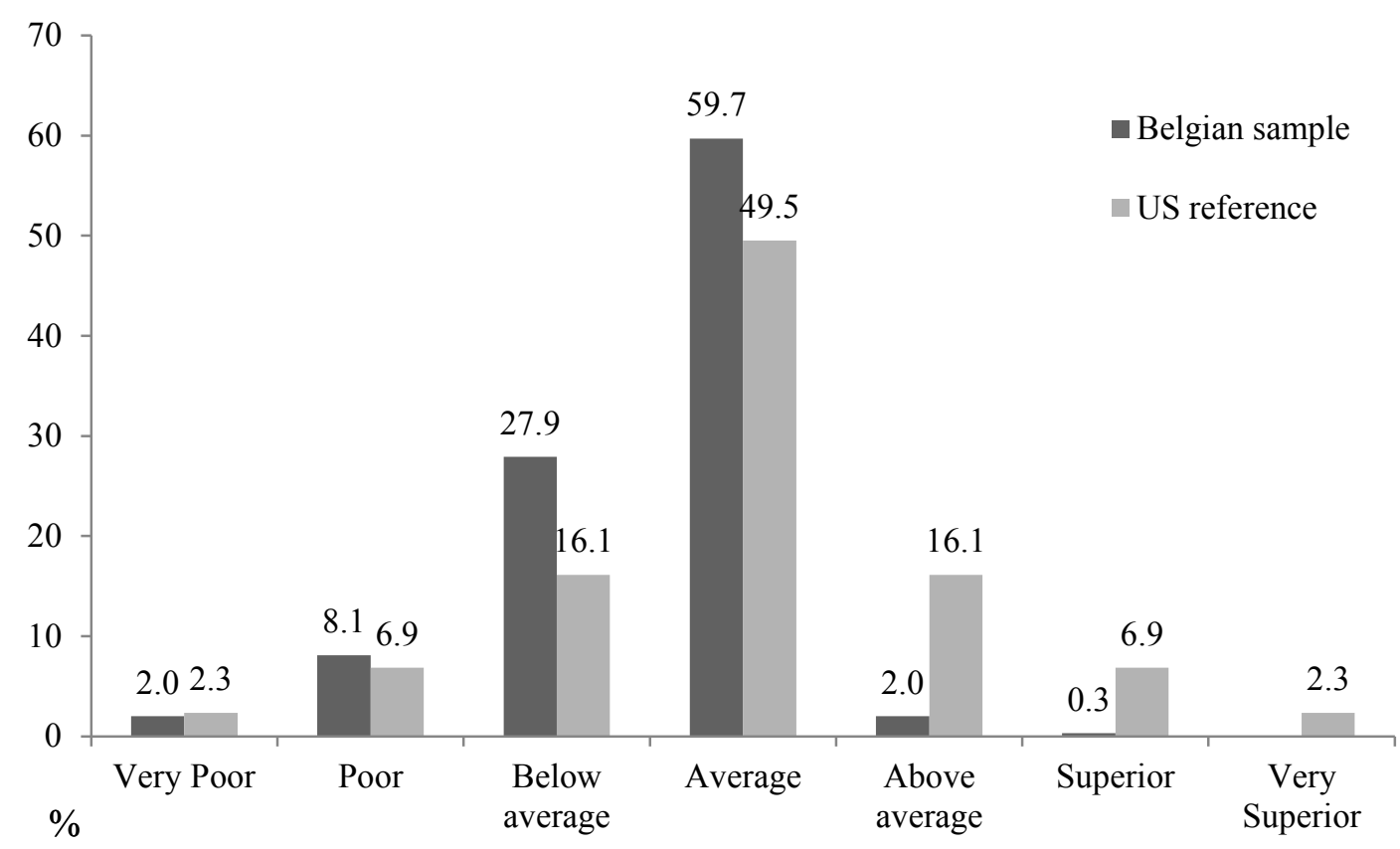

Fig 4. Distribution of Belgian children across the TGMD-2 performance categories for the object control subtest. 


\section{References}

1. Haga M. The relationship between physical fitness and motor competence in children. Child Care Health Dev 2008; 34:329-34.

2. Burton AW, Miller DE. Movement Skill Assessment. Champaign, IL: Human Kinetics; 1998.

3. Stodden DF, Goodway JD, Langendorfer SJ, Roberton MA, Rudisill ME, Garcia C, et al. A Developmental Perspective on the Role of Motor Skill Competence in Physical Activity: An Emergent Relationship. Quest 2008; 60:290-306.

4. Gallahue DL, Ozmun JC, Goodway JD. Understanding Motor Development: Infants, children, adolescents, adults. 7th ed. New Yor, NY: McGraw-Hill; 2012.

5. Clark JE. From the Beginning: A Developmental Perspective on Movement and Mobility. Quest 2005; 57:37-45.

6. Goodway JD, Robinson LE, Crowe H. Gender differences in fundamental motor skill development in disadvantaged preschoolers from two geographical regions. Res $Q$ Exerc Sport 2010; 81:17-24.

7. Robinson LE, Stodden DF, Barnett LM, Lopes VP, Logan SW, Rodrigues LP, et al. Motor Competence and its Effect on Positive Developmental Trajectories of Health. Sport Med 2015.

8. Cools W, De Martelaer K, Samaey C, Andries C. Movement Skill Assessment of Typically Developing Preschool Children: A Review of Seven Movement Skill Assessment Tools. J Sports Sci Med 2009; 8:154-68.

9. Ulrich DA. Test of Gross Motor Development. 2nd ed. Austin, TX: PRO-ED; 2000.

10. Valentini NC. Validity and reliability of the TGMD-2 for Brazilian children. $J$ Mot 
Behav 2012; 44:275-80.

11. Kim C-I, Han D-W, Park I-H. Reliability and Validity of the Test of Gross Motor Development-II in Korean Preschool Children: Applying AHP. Res Dev Disabil 2014; $2-9$.

12. Kiphard EJ, Schilling F. Körperkoordinationstest für Kinder. Weinheim: Beltz Test $\mathrm{GmbH} ; 2007$.

13. Vandorpe B, Vandendriessche J, Lefevre J, Pion J, Vaeyens R, Matthys S, et al. The KörperkoordinationsTest für Kinder: reference values and suitability for 6-12-year-old children in Flanders. Scand J Med Sci Sports 2011; 21:378-88.

14. Lopes VP, Rodrigues LP, Maia JAR, Malina RM. Motor coordination as predictor of physical activity in childhood. Scand J Med Sci Sports 2011; 21:663-9.

15. Cools W, De Martelaer K, Vandaele B, Samaey C, Andries C. Fundamental Movement Skill Development of Four to Six Year-old Preschool Children in Flanders. In: Reilly T, Atkinson G, editors. Contemporary Sport, Leisure and Ergonomics. London: Routledge; 2009:335-52.

16. Miyahara M, Tsujii M, Hanai T, Barnett A, E. Henderson S, Hori M, et al. The Movement Assessment Battery for Children: A preliminary investigation of its usefulness in Japan. Hum Mov Sci 1998 Aug; 17:679-97.

17. Vanvuchelen M, Mulders H, Smeyers K. Onderzoek naar de bruikbaarheid van de recente Amerikaanse Peabody Developmental Motor Scales-2 voor vijfjarige Vlaamse kinderen. Signaal 2003; 45:24-41.

18. Folio MR, Fewell RR. Peabody Developmental Motor Scales. 2nd ed. Austin, TX: PROED; 2000. 
19. OECD. Education at a Glance 2013: OECD Indicators. OECD Publishing; 2013.

20. Simons J, Van Hombeeck C. Toepasbaarheid van de Test of Gross Motor Development Second Edition. Kinevaria 2003; 39:16-21.

21. Van Waelvelde H, Peersman W, Lenoir M, Smits-Engelsman BCM, Henderson SE. The Movement Assessment Battery for Children: Similarities and differences between 4- and 5-year-old children from Flanders and the United States. Pediatr Phys Ther 2008; 20:308.

22. Ahnert J, Schneider W, Bös K. Developmental changes and individual stability of motor abilities from the preschool period to young adulthood. In: Schneider W, Bullock M, editors. Human Development from Early Childhood to Early Adulthood: Findings from a 20 Year Longitudinal Study. New York, NY: Psychology Press; 2009:35-62.

23. Barnett LM, van Beurden E, Morgan PJ, Brooks LO, Beard JR. Gender differences in motor skill proficiency from childhood to adolescence: a longitudinal study. Res Q Exerc Sport 2010; 81:162-70.

24. Malina RM, Bouchard C, Bar-Or O. Growth, maturation and physical activity. 2nd ed. Champaign, IL: Human Kinetics; 2004.

25. Wrotniak BH, Epstein LH, Dorn JM, Jones KE, Kondilis V a. The relationship between motor proficiency and physical activity in children. Pediatrics 2006; 118:1758-65.

26. Thomas JR, French KE. Gender differences across age in motor performance: A metaanalysis. Psychol Bull 1985; 98:260-82.

27. Bardid F, Rudd JR, Lenoir M, Polman R, Barnett LM. Cross-cultural comparison of motor competence in children from Australia and Belgium. Front Psychol 2015; 6:1-8.

28. Hardy LL, Barnett L, Espinel P, Okely AD. Thirteen-year trends in child and adolescent 
fundamental movement skills: 1997-2010. Med Sci Sports Exerc 2013; 45:1965-70.

29. Dollman J, Norton K, Norton L. Evidence for secular trends in children's physical activity behaviour. Br J Sports Med 2005; 39:892-7.

30. Rudd J, Butson ML, Barnett L, Farrow D, Berry J, Borkoles E, et al. A holistic measurement model of movement competency in children. J Sports Sci 2015; 1-9. 